\title{
Optimized ROI size on ADC measurements of normal pancreas, pancreatic cancer and mass-forming chronic pancreatitis
}

\author{
Chao Ma ${ }^{1}$, Jing Li ${ }^{1}$, Mbaiaoure Barak Boukar ${ }^{1}$, Panpan Yang ${ }^{1}$, Li Wang ${ }^{1}$, Luguang \\ Chen $^{1}$, Li Su${ }^{2}$, Jianxun Qu ${ }^{3}$, Shi-Yue Chen ${ }^{1}$, Qiang Hao ${ }^{1}$ and Jian-Ping Lu ${ }^{1}$ \\ ${ }^{1}$ Department of Radiology, Changhai Hospital of Shanghai, The Second Military Medical University, Shanghai, China \\ ${ }^{2}$ School of Pharmacy, Second Military Medical University, Shanghai, China \\ ${ }^{3}$ GE Healthcare, MR Group, Shanghai, China
}

Correspondence to: Jian-Ping Lu, email: cjr.lujianping@vip.163.com

Keywords: DWI, apparent diffusion coefficient (ADC), pancreatic cancer, region of interest (ROI), chronic pancreatitis Received: October 19, $2016 \quad$ Accepted: May 23, $2017 \quad$ Published: June 12, 2017

Copyright: Ma et al. This is an open-access article distributed under the terms of the Creative Commons Attribution License 3.0 (CC BY 3.0), which permits unrestricted use, distribution, and reproduction in any medium, provided the original author and source are credited.

\section{ABSTRACT}

Objectives: To investigate the effects of region of interest (ROI) sizes on apparent diffusion coefficient (ADC) measurements for the differentiation of normal pancreas (NP), pancreatic ductal adenocarcinoma (PDAC) and mass-forming chronic pancreatitis (MFCP).

Results: There were no significant differences for the mean ADCs measured by 12 different-size ROIs for MFCP, or PDAC and NP $(P=\mathbf{0 . 8 5 8 - 1 . 0})$. With the increase of ROI size ( $\geq 55 \mathrm{~mm}^{2}$ ), ADCs of PDAC were significantly lower than those of NP (all $P<0.05$ ), but there was no difference of the accuracy in ADC for differentiating the two groups only at a ROI size of $214 \mathrm{~mm}^{2}$. When ROI size was above $99 \mathrm{~mm}^{2}$, ADCs of MFCP were significantly lower than those of NP (all $P<0.05$ ). There were no significant differences for any of the mean ADCs measured by 12 different-size ROIs between PDAC and MFCP $(P>0.05)$.

Materials and Methods: Diffusion-weighted imaging (DWI) was performed on 89 participants: 64 with PDAC, 7 with MFCP, as well as 18 healthy volunteers. ADC maps were created using mono-exponential model. A homemade software was used to measure the mean ADC values of 12 concentric round ROIs (areas: 15, 46, 55, 82, $99,121,134,152,161,189,214,223$, and $245 \mathrm{~mm}^{2}$ ) for the mass of lesions and the NP tissue.

Conclusions: In ADC measurements, the optimized ROI size is $214 \mathbf{~ m m}^{2}$ for the differentiation of PDAC and NP; ROI size of $\geq 99 \mathrm{~mm}^{2}$ is recommended to differentiate between MFCP and NP. ADC was not useful for the differentiation of PDAC and MFCP.

\section{INTRODUCTION}

Differential diagnosis of mass-forming chronic pancreatitis (MFCP) and pancreatic ductal adenocarcinoma (PDAC) is of clinical significance due to the different treatment strategies [1,2], and yet this remains challenging in practice because of the similarity of imaging presentations for the two different entities [3-6]. Diffusion-weighted imaging (DWI) with quantitative measurement of apparent diffusion coefficient (ADC) values provide an alternative to conventional anatomical magnetic resonance imaging (MRI), such as T1- (T1WI) and T2-weighted imaging (T2WI), for the detection and characterization of cystic and solid pancreatic tumors in clinical practice [7].

Some studies have been carried out to investigate the possibility to differentiate MFCP from PDAC by using qualitative DWI and quantitative ADC [7-12]. 
However, the use of mean ADC values to differentiate MFCP from PDAC may still be challenging, possibly due to the variable proportions of fibrosis and inflammation in MFCP, fibrosis and cell density in tumors, and literature data are inhomogeneous and controversial [8-12]. In terms of the measurement, this could be caused by the large variation in the region of interest (ROI) sizes $[13,14]$ in these studies (ranging from 19 to $879 \mathrm{~mm}^{2}$ ) [8-12]. The avoidance of the placement of smaller ROIs within lesions is commonly recommended, particularly for the response assessment studies $[7,15]$. There is a clear need for the standardization of ROI sizes for ADC measurements of pancreatic diseases to enable the validation of this quantitative parameter as a qualified biomarker for longitudinal clinical trials. To our knowledge, the effect of ROI size on ADC measurements in normal pancreatic tissue or pancreatic lesions have rarely been studied. Thus, the aim of this study was to investigate the influences of ROI size in ADC measurements for the differentiation between normal pancreas (NP), PDAC and MFCP.

\section{RESULTS}

Two repeated DWI experiments of phantom using a standard eight-element phased array body coil for clinical examination revealed similar results. The mean ADCs of the water with different ROI sizes range from $1.895 \pm 0.056$ to $1.901 \pm 0.053 \times 10^{-3} \mathrm{~mm}^{2} / \mathrm{s}$ (Figure 1$)$.

The mean ADC values of three participant groups (PDAC, MFCP and NP) with different ROI sizes are summarized and shown in Table 1. The typical averaged ADC curves of PDAC (64 cases), MFCP (7 cases), NP (18 cases) and water phantom (10 cases) with different ROI sizes are demonstrated in Figure 1.

ANOVA results revealed ROI size had no significant effects on the mean ADC values for all the three groups $(P=0.858-1.0)$. Comparisons of the mean ADC values were performed and the results demonstrated significant differences among the three participant groups while the ROI size was above $55 \mathrm{~mm}^{2}$. The multiple comparisons results demonstrated that the mean ADCs of PDAC were significantly lower than those of NP (all $P<0.05$ ) at a ROI size of $\geq 55 \mathrm{~mm}^{2}$, in addition, the mean ADCs of MFCP were significantly lower than those of NP (all $P<0.05$ ) while at a ROI size was $\geq 99 \mathrm{~mm}^{2}$. However, there were no significant differences between PDAC and MFCP for any of the mean ADCs measured by 12 different-size ROIs (all $P>0.05$ ).

ROC analyses results showed that there were no differences of the accuracy in ADC for differentiating between the PDAC and NP only at a ROI size of $214 \mathrm{~mm}^{2}$ (Table 2), and no difference of the accuracy in ADC were observed for differentiating between MFCP and NP while at a ROI size was $\geq 99 \mathrm{~mm}^{2}$ (Table 3, Figure 2).

\section{DISCUSSION}

DWI has been widely used to detect and evaluate various tumors by noninvasively measuring ADC [16]. In pancreas imaging, a large number of studies have demonstrated significantly lower ADCs in PDAC than those in benign pancreas tissue [17-26]. As a supplement technique to conventional MR imaging, DWI improved the sensitivity of PDAC detection (with sensitivity and specificity up to $97 \%$ and $92 \%$, respectively) [27]. However, quantitative ADC failed to differentiate the solid pancreatic lesions, due to the fact that a wide overlap in mean ADC values for different types [8, 28]. Takeuchi M, et al. [9] and Lee SS, et al. [8] reported that lower ADC values were observed in MFCP compared to PDAC. Contrarily, another two studies found the mean ADC values of PDAC was significantly lower than those of MFCP $[4,10]$. In our study, no significant difference was observed between the mean ADC values of MFCP and PDAC, which was similar to the reported results of Wiggermann $P$, et al. [11] and Sandrasegaran $\mathrm{K}$, et al. [12]. Areas of fibrosis and focal inflammatory reactions might explain the difficulty in differentiating MFCP from PDACs by using the mean ADCs [11].

In the ADC measurements for pancreatic lesions, although no formal recommendation was reported before, a minimum size of $100 \mathrm{~mm}^{2}$ was commonly used [7]. Our results showed that ROI size has remarkable influence on the differentiation between NP, PDAC and MFCP, confirmed by the fact that the mean ADCs of PDAC were significantly lower than those of NP (all $P<0.05$ ) when with ROI $\geq 55 \mathrm{~mm}^{2}$, and the mean ADCs of MFCP were significantly lower than those of NP (all $P<0.05$ ) when ROI $\geq 99 \mathrm{~mm}^{2}$. Additionally, according to the ROC analyses results, a ROI size of $\geq 214 \mathrm{~mm}^{2}$ is recommended for the differentiation of PDAC and NP; and a ROI size of $\geq 99 \mathrm{~mm}^{2}$ is recommended to differentiate between MFCP and NP.

Three ROI methods, including the whole-volume ROI, single-slice ROI and small solid-sample ROI approaches, have been used to obtain ADC measurements from tumors [8-15, 17-28]. In our previous studies, we found that despite its large inter-observer variability, small solid-sample ROIs on tumors provided greater diagnostic performance in the assessment of PDAC compared with single-slice and whole-volume ROI methods [29]. Additionally, it is difficult to perform ADC measurements with whole-volume or single-slice ROI method in many tumors of patients with PDAC because of the unclear boundaries of tumors on DWI images [23, 29, 30]. Solidsample ROI is the most commonly used approach for ADC measurements of PDAC [8, 10, 11, 18, 20, 22, 23, 25]. The ROIs in the lesions are delineated to avoid pancreatic ducts, cystic lesions, and imaging artifacts. Therefore, the small solid-sample ROI approach was used in this study. 
Our study has several limitations. Firstly, the number of patients and control group was small, and only 7 patients were included in MFCP group. A larger sample size is required to confirm our results in future work. Secondly, in order to decrease the imaging variables and keep them as constant and homogeneous as possible, all the MR examinations of all patients were performed with the same imaging protocols and parameters on a $3.0-\mathrm{T}$
MRI system from a single vendor, whereas such an ideal scenario may not be available in actual daily clinical practice. In the future, well-designed, multicenter studies are needed to better determine the most appropriate usage of ADC in the field of pancreatic disease. Thirdly, our DWI experiments were performed with a relatively low $\mathrm{b}$ value $\left(600 \mathrm{~s} / \mathrm{mm}^{2}\right)$ to minimize motion artifacts and to improve the signal-to-noise ratio in pancreas, while it

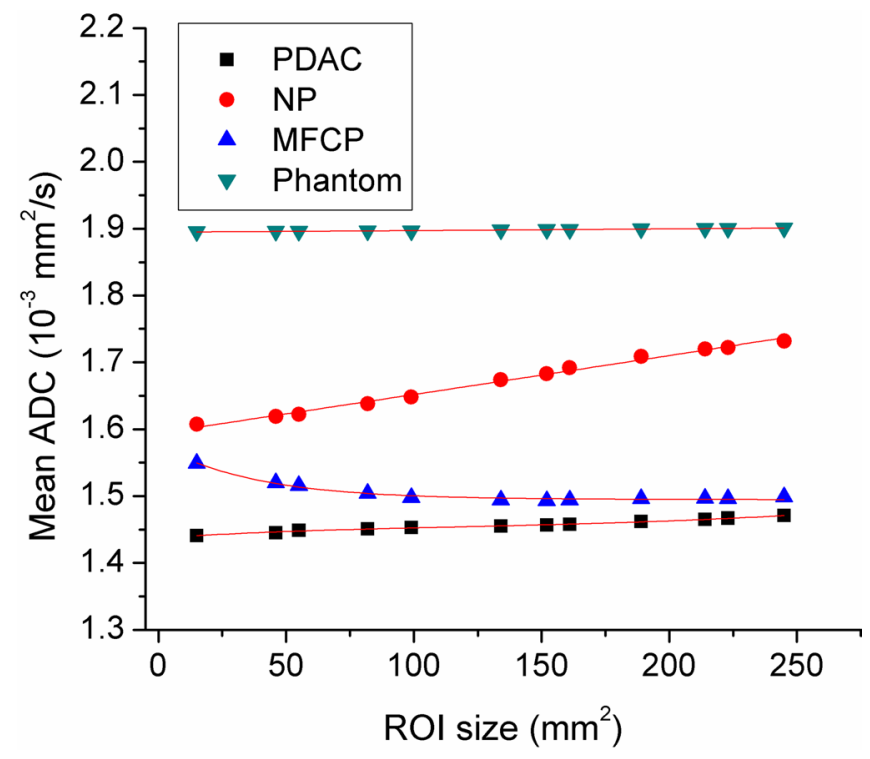

Figure 1: The mean apparent diffusion coefficient (ADC) curves for pancreatic ductal adenocarcinoma (PDAC), massformed chronic pancreatitis (MFCP), normal pancreas (NP) and water phantom.

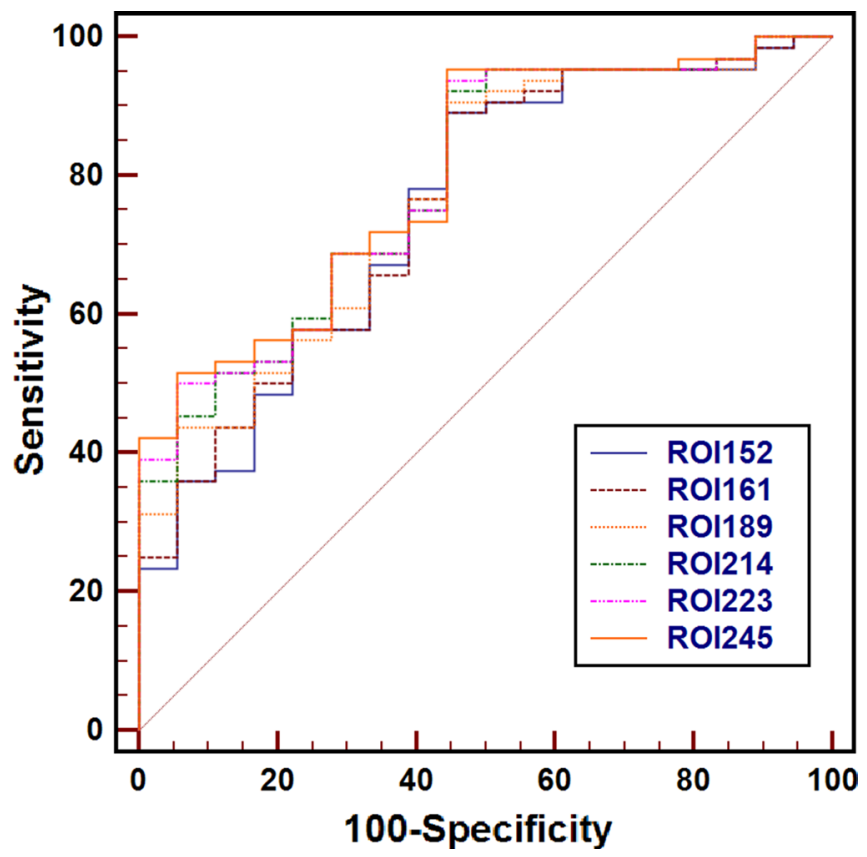

Figure 2: Receiver operating characteristic curves for the mean apparent diffusion coefficient measured with regions of interest (ROIs) of $152 \mathrm{~mm}^{2}$ to $245 \mathrm{~mm}^{2}$ for the differentiating between pancreatic ductal adenocarcinoma (PDAC) from normal pancreas (NP). There was no difference of the accuracy in ADC for differentiating between the PDAC and NP only at ROI size of $214 \mathrm{~mm}^{2}$ or higher. 
Table 1: Mean ADC values $\left(\times 10^{-3} \mathrm{~mm}^{2} / \mathrm{s}\right)$ of PDAC, FP, NP measured by using 12 concentric round ROIs and comparisons of the mean values among 3 groups

\begin{tabular}{ccccc}
\hline ROI size $\left(\mathbf{m m}^{2}\right)$ & PDAC (64) & MFCP (7) & NP(18) & $P^{*}$ \\
\hline 15 & $1.44 \pm 0.28$ & $1.55 \pm 0.75$ & $1.61 \pm 0.30$ & 0.103 \\
46 & $1.45 \pm 0.26$ & $1.52 \pm 0.72$ & $1.62 \pm 0.29$ & 0.055 \\
55 & $1.45 \pm 0.29$ & $1.52 \pm 0.71$ & $1.62 \pm 0.28$ & $\mathbf{0 . 0 4 8}^{*}$ \\
82 & $1.45 \pm 0.25$ & $1.50 \pm 0.70$ & $1.64 \pm 0.26$ & $\mathbf{0 . 0 3 9}^{*}$ \\
99 & $1.45 \pm 0.25$ & $1.50 \pm 0.69$ & $1.65 \pm 0.25$ & $\mathbf{0 . 0 2 6}^{* *}$ \\
134 & $1.46 \pm 0.24$ & $1.49 \pm 0.67$ & $1.67 \pm 0.24$ & $\mathbf{0 . 0 1 1}^{* *}$ \\
152 & $1.46 \pm 0.24$ & $1.49 \pm 0.66$ & $1.68 \pm 0.23$ & $\mathbf{0 . 0 0 6}^{* *}$ \\
161 & $1.46 \pm 0.24$ & $1.49 \pm 0.66$ & $1.69 \pm 0.24$ & $\mathbf{0 . 0 0 5}^{* *}$ \\
189 & $1.46 \pm 0.24$ & $1.50 \pm 0.65$ & $1.71 \pm 0.23$ & $\mathbf{0 . 0 0 3}^{* *}$ \\
214 & $1.46 \pm 0.24$ & $1.50 \pm 0.65$ & $1.72 \pm 0.23$ & $\mathbf{0 . 0 0 1}^{* *}$ \\
223 & $1.47 \pm 0.23$ & $1.50 \pm 0.64$ & $1.72 \pm 0.22$ & $\mathbf{0 . 0 0 1}^{* *}$ \\
245 & $1.47 \pm 0.23$ & $1.50 \pm 0.63$ & $1.73 \pm 0.22$ & $\mathbf{0 . 0 0 1}^{* *}$ \\
\hline
\end{tabular}

ADC, apparent diffusion coefficient; PDAC, pancreatic ductal adenocarcinoma; MFCP, mass-formed chronic pancreatitis; NP, normal pancreas; SD, standard deviation.

"Post-hoc analyses show significant differences between PDAC and NP $(P<0.05)$.

${ }^{* *}$ Post-hoc analyses show significant differences both between PDAC and NP, FP and NP groups.

"Kruskal-Wallis tests.

Table 2: Results from the ROC analyses of the different ROIs derived mean ADCs to distinguish between pancreatic adenocarcinoma and healthy pancreas

\begin{tabular}{|c|c|c|c|c|c|c|c|}
\hline $\begin{array}{c}\text { ROI size } \\
\left(\mathbf{m m}^{2}\right)\end{array}$ & $\begin{array}{l}\text { Optimal cutoff values } \\
\qquad\left(\times 10^{-3} \mathrm{~mm}^{2} / \mathrm{s}\right)\end{array}$ & $\begin{array}{l}\mathrm{AUC} \pm \mathrm{SE} \\
(95 \% \mathrm{CI})\end{array}$ & Sensitivities (95\% CI) & Specificities (95\% CI) & PPV (\%) & NPV (\%) & $\operatorname{ACC}(\%)$ \\
\hline 55 & 1.70 & $\begin{array}{c}0.687 \pm 0.079 \\
(0.575-0.785)\end{array}$ & $\begin{array}{c}89.1 \\
(78.8-95.5)\end{array}$ & $\begin{array}{c}50.0 \\
(26.0-74.0)\end{array}$ & 86.4 & 56.3 & 80.5 \\
\hline 82 & 1.72 & $\begin{array}{c}0.694 \pm 0.077 \\
(0.582-0.791)\end{array}$ & $\begin{array}{c}90.6 \\
(80.7-96.5)\end{array}$ & $\begin{array}{c}50.0 \\
(26.0-74.0)\end{array}$ & 86.6 & 59.9 & 81.7 \\
\hline 99 & 1.73 & $\begin{array}{c}0.707 \pm 0.074^{*} \\
(0.596-0.802)\end{array}$ & $\begin{array}{c}90.6 \\
(80.7-96.5)\end{array}$ & $\begin{array}{c}50.0 \\
(26.0-74.0)\end{array}$ & 86.6 & 59.9 & 81.7 \\
\hline 134 & 1.74 & $\begin{array}{c}0.731 \pm 0.070 \\
(0.622-0.823)\end{array}$ & $\begin{array}{c}90.6 \\
(80.7-96.5)\end{array}$ & $\begin{array}{c}50.0 \\
(26.0-74.0)\end{array}$ & 86.6 & 59.9 & 81.7 \\
\hline 152 & 1.70 & $\begin{array}{c}0.751 \pm 0.067 \\
(0.643-0.840)\end{array}$ & $\begin{array}{c}89.1 \\
(78.8-95.5)\end{array}$ & $\begin{array}{c}55.6 \\
(30.8-78.5)\end{array}$ & 87.7 & 58.9 & 81.7 \\
\hline 161 & 1.70 & $\begin{array}{c}0.756 \pm 0.065 \\
(0.649-0.844)\end{array}$ & $\begin{array}{c}89.1 \\
(78.8-95.5)\end{array}$ & $\begin{array}{c}55.6 \\
(30.8-78.5)\end{array}$ & 87.7 & 58.9 & 81.7 \\
\hline 189 & 1.75 & $\begin{array}{c}0.770 \pm 0.062 \\
(0.664-0.856)\end{array}$ & $\begin{array}{c}90.6 \\
(80.7-96.5)\end{array}$ & $\begin{array}{c}55.6 \\
(30.8-78.5)\end{array}$ & 87.9 & 62.5 & 82.9 \\
\hline 214 & 1.79 & $\begin{array}{c}0.788 \pm 0.059 \\
(0.684-0.871)\end{array}$ & $\begin{array}{c}92.2 \\
(82.7-97.4)\end{array}$ & $\begin{array}{c}55.6 \\
(30.8-78.5)\end{array}$ & 88.1 & 66.7 & 84.2 \\
\hline 223 & 1.79 & $\begin{array}{c}0.793 \pm 0.058 \\
(0.689-0.874)\end{array}$ & $\begin{array}{c}93.8 \\
(84.8-98.3)\end{array}$ & $\begin{array}{c}55.6 \\
(30.8-78.5)\end{array}$ & 88.3 & 71.6 & 85.4 \\
\hline 245 & 1.79 & $\begin{array}{c}0.800 \pm 0.056 \\
(0.697-0.881)\end{array}$ & $\begin{array}{c}95.3 \\
(86.9-99.0)\end{array}$ & $\begin{array}{c}55.6 \\
(30.8-78.5)\end{array}$ & 88.4 & 76.9 & 86.6 \\
\hline
\end{tabular}

ROC, Receiver operating characteristic curve; AUC, area under curve. ADC, apparent diffusion coefficient; SE, standard error; CI, confidence interval; ROI, region of interest; PPV, positive predictive value; NPV, negative predictive value; ACC, accuracy. 
Table 3: Results from the ROC analyses of the different ROIs derived mean ADCs to distinguish between MFCP and healthy pancreas

\begin{tabular}{|c|c|c|c|c|c|c|c|}
\hline $\begin{array}{c}\text { ROI size } \\
\left(\mathrm{mm}^{2}\right)\end{array}$ & $\begin{array}{l}\text { Optimal cutoff values } \\
\qquad\left(\times 10^{-3} \mathrm{~mm}^{2} / \mathrm{s}\right.\end{array}$ & $\begin{array}{l}\mathrm{AUC} \pm \mathrm{SE} \\
(95 \% \mathrm{CI})\end{array}$ & Sensitivities (95\% CI) & Specificities $(95 \% \mathrm{CI})$ & PPV (\%) & NPV (\%) & $\operatorname{ACC}(\%)$ \\
\hline 99 & 1.51 & $\begin{array}{c}0.659 \pm 0.170^{*} \\
(0.444-0.835)\end{array}$ & $\begin{array}{c}71.4 \\
(29.0-96.3)\end{array}$ & $\begin{array}{c}72.2 \\
(46.5-90.3)\end{array}$ & 50.0 & 86.7 & 72.0 \\
\hline 134 & 1.27 & $\begin{array}{c}0.675 \pm 0.174 \\
(0.460-0.847)\end{array}$ & $\begin{array}{c}57.1 \\
(18.4-90.1)\end{array}$ & $\begin{array}{c}100.0 \\
(81.5-100.0)\end{array}$ & 100 & 87.5 & 88.0 \\
\hline 152 & 1.27 & $\begin{array}{c}0.683 \pm 0.170 \\
(0.468-0.852)\end{array}$ & $\begin{array}{c}57.1 \\
(18.4-90.1)\end{array}$ & $\begin{array}{c}100.0 \\
(81.5-100.0)\end{array}$ & 100 & 87.5 & 88.0 \\
\hline 161 & 1.27 & $\begin{array}{c}0.683 \pm 0.170 \\
(0.468-0.852)\end{array}$ & $\begin{array}{c}57.1 \\
(18.4-90.1)\end{array}$ & $\begin{array}{c}100.0 \\
(81.5-100.0)\end{array}$ & 100 & 87.5 & 88.0 \\
\hline 189 & 1.27 & $\begin{array}{c}0.690 \pm 0.170 \\
(0.476-0.858)\end{array}$ & $\begin{array}{c}57.1 \\
(18.4-90.1)\end{array}$ & $\begin{array}{c}100.0 \\
(81.5-100.0)\end{array}$ & 100 & 87.5 & 88.0 \\
\hline 214 & 1.27 & $\begin{array}{c}0.690 \pm 0.170 \\
(0.476-0.858)\end{array}$ & $\begin{array}{c}57.1 \\
(18.4-90.1)\end{array}$ & $\begin{array}{c}100.0 \\
(81.5-100.0)\end{array}$ & 100 & 87.5 & 88.0 \\
\hline 223 & 1.27 & $\begin{array}{c}0.690 \pm 0.170 \\
(0.476-0.858)\end{array}$ & $\begin{array}{c}57.1 \\
(18.4-90.1)\end{array}$ & $\begin{array}{c}100.0 \\
(81.5-100.0)\end{array}$ & 100 & 87.5 & 88.0 \\
\hline 245 & 1.27 & $\begin{array}{c}0.690 \pm 0.170 \\
(0.476-0.858)\end{array}$ & $\begin{array}{c}57.1 \\
(18.4-90.1)\end{array}$ & $\begin{array}{c}100.0 \\
(81.5-100.0)\end{array}$ & 100 & 87.5 & 88.0 \\
\hline
\end{tabular}

ROC, operating characteristic curve; AUC, area under curve. ADC, apparent diffusion coefficient; SE, standard error; CI, confidence interval; ROI, region of interest; PPV, positive predictive value; NPV, negative predictive value; ACC, accuracy.

has been shown that the use of higher $b$ values may be more sensitive to reflect true diffusion [19]. Furthermore, only two $\mathrm{b}$ values $\left(0\right.$ and $\left.600 \mathrm{~s} / \mathrm{mm}^{2}\right)$ were performed in our study to reduce the scan time in the clinical setting, although ideally multiple $\mathrm{b}$ values should be used for more accurate measurements of ADC values [31,32].

In conclusion, this focused DWI study demonstrated that ROI size had a considerable influence on the differentiation between NP, PDAC and MFCP at 3.0T. A ROI size of $\geq 214 \mathrm{~mm}^{2}$ is recommended for the differentiation between PDAC and NP; and a ROI size of $\geq 99 \mathrm{~mm}^{2}$ is recommended to differentiate between MFCP and NP.

\section{MATERIALS AND METHODS}

\section{Study design and population}

The study was composed of phantom experiments and in vivo scans of healthy subjects and patients. A round water phantom $\left(18-\mathrm{cm}\right.$ in diameter, $\left.20^{\circ} \mathrm{C}\right)$ was imaged to validate the reliability of our scanner and demonstrate the results of the ideal mean ADC values with different ROIs as a reference measurement. All experiments were performed on a 3.0-T MRI system (Signa HDxt, GE Healthcare, Milwaukee, WI, USA) with a $40 \mathrm{mT} / \mathrm{m}$ maximum gradient strength and a peak slew rate of $150 \mathrm{~T} / \mathrm{m} / \mathrm{s}$. A body coil was used for signal transmission and an eight-element phased array coil placed over the abdomen was used for signal acquisition.

This retrospective study was reviewed and approved by the ethics committee of our hospital, and informed consent was waived from all the participants. Between
January 2014 and February 2017, sixty-four patients with pathology-proven PDAC, seven patients with pathologyproven MFCP and eighteen healthy volunteers were included in the study. Mean age of the healthy volunteer group was $46.8 \pm 12.0$ years (range: $27-65$ years), whereas mean age of the PDAC and MFCP groups was $61.1 \pm 8.7$ years; years (range: $40-78$ years) and $47.3 \pm$ 10.7 years (range: $32-66$ years), respectively. The mean lesion size was $37 \pm 9 \mathrm{~mm}$ (range, $21-70 \mathrm{~mm}$ ) and 39 $\pm 12 \mathrm{~mm}$ (range, 27-64 mm) for PDAC and MFCP, respectively.

\section{In Vivo imaging}

All of the 89 participants were preoperatively examined with conventional MRI protocols and transversal respiratory triggered single-shot echo-planar DWI (diffusion gradients along the physical $\mathrm{x}, \mathrm{y}$, and $\mathrm{z}$ axes), using $\mathrm{b}$ values of 0 and $600 \mathrm{~s} / \mathrm{mm}^{2}$. Spectral selective presaturation with inversion recovery was used to achieve fat saturation. The main scan parameters and the scanning order of sequences were presented in Table 4 . Out of the whole cohort, only 71 patients underwent contrast-enhanced liver acceleration volume acquisition (LAVA), which was performed with Gadopentetate Dimeglumine injection (physiological saline, $10-15 \mathrm{ml}$; media, $0.2-0.3 \mathrm{ml} / \mathrm{kg}$ ) at the end of the study.

\section{Phantom experiments}

In the phantom study, the phantom was scanned using single-shot echo-planar DWI. The scan parameters were $\mathrm{TR}=3000 \mathrm{~ms}, \mathrm{TE}=58.3 \mathrm{~ms}, \mathrm{FOV}=38.0 \times 30.4 \mathrm{~cm}^{2}$, 
Table 4: The main parameters of MRI protocol

\begin{tabular}{|c|c|c|c|c|c|c|c|c|c|}
\hline Protocols & TR/TE(ms) & FOV $(\mathbf{m m})$ & Matrix & Thickness/gap(mm) & Flip angle $\left({ }^{\circ}\right)$ & Slices & NEX & Bandwidth(kHz) & Speed factor \\
\hline $\mathrm{MRCP}$ & $7000 / 1253.4$ & $300 \times 300$ & $288 \times 288$ & $64 / 0$ & - & 6 & 0.92 & 31.2 & - \\
\hline $\mathrm{T} 2 \mathrm{WI}$ & $6316 / 73.8$ & $360 \sim 400$ & $320 \times 192$ & $5 / 1$ & 90 & 20 & 2 & 83.3 & 2 \\
\hline DWI & $6000 / 58.6$ & $380 \times 304$ & $128 \times 96$ & $5 / 1$ & 90 & 20 & $2 / 4^{*}$ & 250 & 2 \\
\hline T1WI & $2.5 / 1.1$ & $440 \times 418$ & $256 \times 180$ & $2.5 / 0$ & 11 & 84 & 0.70 & 125 & 2 \\
\hline
\end{tabular}

${ }^{*} \mathrm{NEX}=2$ for DWI at $\mathrm{b}_{0}, \mathrm{NEX}=4$ for DWI at $\mathrm{b}_{600}$.

MRCP, magnetic resonance cholangiopancreatography; T2WI, T2-weighted imaging; DWI, diffusing weighted imaging; T1WI, T1-weighted imaging.

matrix $=128 \times 96$, slice $/$ gap thickness $=5 \mathrm{~mm} / 1.5 \mathrm{~mm}$ and $\mathrm{NEX}=1$ and 4 for $\mathrm{b}_{0}$ and $\mathrm{b}_{600}$, respectively.

\section{Data analysis}

ADC maps were derived from the DWI images using a monoexponential model $\left(\mathrm{ADC}=\left[\ln \left(\mathrm{SI}_{\mathrm{b} 0} / \mathrm{SI}_{\mathrm{b} 600}\right)\right] / 600\right)$ on a workstation (Function V9.4.05, Advanced Workstation 4.4, GE Healthcare). The anonymous MR images of each participant were sorted in a random order. A homemade software was used to measure the mean ADC value within each of 12 concentric round ROIs (areas: 15, 46, $55,82,99,121,134,152,161,189,214,223$, and 245 $\mathrm{mm}^{2}$ with pixel numbers: $7,21,25,37,45,61,69,73$, $86,97,101$ and 111, respectively) drawn on the solid part of the mass of lesions and the head of NP. ADC values were measured by two observers (with 11 and 6 years of experience in abdominal radiology) (Figures 3 and 4), avoiding pancreatic ducts and cystic lesions by referring to other MRI images such as T2WI or T1WI. Water phantom

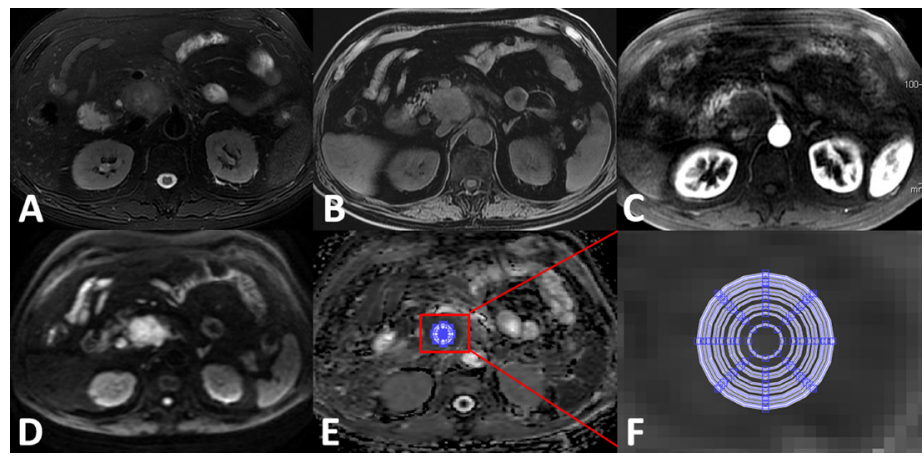

Figure 3: Apparent diffusion coefficient (ADC) measurements for pancreatic ductal adenocarcinoma at the head of the pancreas. (A) Axial T2WI; (B) Axial precontrast T1WI; (C) Axial contrast-enhanced arterial phase T1WI demonstrating the hypovascularity of the mass; (D) DWI image $\left(b=600 \mathrm{~s} / \mathrm{mm}^{2}\right)$ clearly demarcated hyperintensity while compared with the surrounding pancreas tissues; (E) ADC map; (F) zoomed-in ADC map that indicates 12 concentric round ROIs (areas 15, 46, 55, 82, 99, 121, 134, 161, $189,214,223$, and $245 \mathrm{~mm}^{2}$ were used for mean ADC measurements.

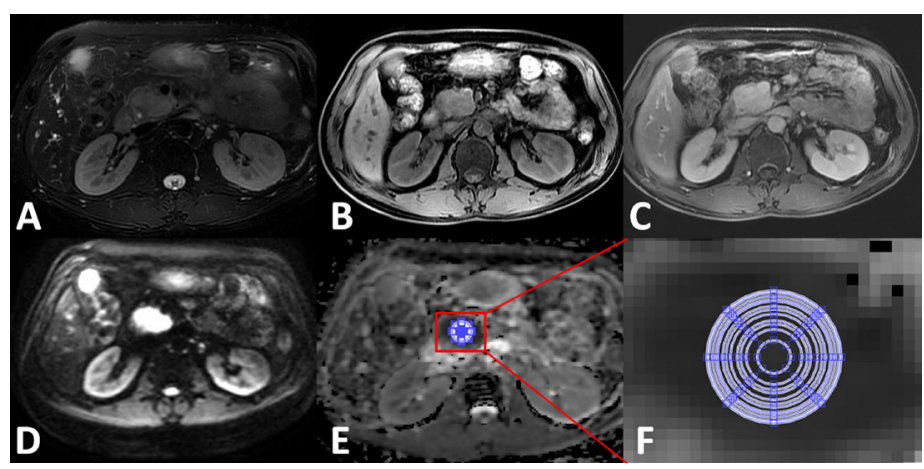

Figure 4: Apparent diffusion coefficient (ADC) measurements for mass-formed chronic pancreatitis at the head of the pancreas. (A) Axial T2WI; (B) Axial precontrast T1WI; (C) Axial contrast-enhanced arterial phase T1WI; (D) DWI image (b=600 s/ $\left.\mathrm{mm}^{2}\right)$ clearly demarcated hyperintensity while compared with the surrounding pancreas tissues; (E) ADC map; (F) zoomed-in ADC map that indicates 12 concentric round ROIs (areas 15, 46, 55, 82, 99, 121, 134, 161, 189, 214, 223, and $245 \mathrm{~mm}^{2}$ were used for mean ADC measurements. 
was used to calculate the ideal mean ADCs with 10 times random measurements as a reference.

\section{Statistical analysis}

Statistical analyses were performed using Medcalc software (Version 13.0.0.0, MedCalc software). The mean ADCs obtained from the 12 different-sized ROIs were compared by one-way repeated analysis of variance (ANOVA) for each group of PDAC, MRCP or NP. $P<0.05$ was considered as statistically significant. The comparison of mean $\mathrm{ADC}$ values for each ROI size among the three groups were analyzed using Kruskal-Wallis tests and a test for pairwise comparison of subgroups were conducted according to Conover. In addition, receiver operating characteristics (ROC) analyses were used to identify the diagnostic performances of the mean ADCs for the differentiation between NP, PDAC and MFCP.

\section{CONFLICTS OF INTEREST}

None.

\section{FUNDING}

This work was supported by the Natural Science Foundation of Shanghai (14ZR1408300); medical guidance project of Shanghai Municipal Science and Technology Commission (14411960100); the 1255 Academic Discipline Project of Shanghai Changhai Hospital (CH125520800).

\section{REFERENCES}

1. Majumder S, Chari ST. Chronic pancreatitis. Lancet. 2016; 387:1957-1966.

2. Taylor B. Carcinoma of the head of the pancreas versus chronic pancreatitis: diagnostic dilemma with significant consequences. World J Surg. 2003; 27:1249-1257.

3. Fusari M, Maurea S, Imbriaco M, Mollica C, Avitabile G, Soscia F, Camera L, Salvatore M. Comparison between multislice $\mathrm{CT}$ and MR imaging in the diagnostic evaluation of patients with pancreatic masses. Radiol Med. 2010; 115:453-466.

4. Huang WC, Sheng J, Chen SY, Lu JP. Differentiation between pancreatic carcinoma and mass-forming chronic pancreatitis: usefulness of high $b$ value diffusion-weighted imaging. J Dig Dis. 2011; 12:401-408.

5. Hidalgo M, Cascinu S, Kleeff J, Labianca R, Löhr JM, Neoptolemos J, Real FX, Van Laethem JL, Heinemann V. Addressing the challenges of pancreatic cancer: future directions for improving outcomes. Pancreatology. 2015; 15:8-18.

6. Ma C, Li YJ, Pan CS, Wang H, Wang J, Chen SY, Lu JP. High resolution diffusion weighted magnetic resonance imaging of the pancreas using reduced field of view single- shot echo-planar imaging at $3 \mathrm{~T}$. Magn Reson Imaging. 2014; 32:125-1231.

7. Barral M, Taouli B, Guiu B, Koh DM, Luciani A, Manfredi R, Vilgrain V, Hoeffel C, Kanematsu M, Soyer P. Diffusion-weighted MR imaging of the pancreas: current status and recommendations. Radiology. 2015; 274:45-63.

8. Lee SS, Byun JH, Park BJ, Park SH, Kim N, Park B, Kim JK, Lee MG. Quantitative analysis of diffusionweighted magnetic resonance imaging of the pancreas: usefulness in characterizing solid pancreatic masses. J Magn Reson Imaging. 2008; 28:928-936.

9. Takeuchi M, Matsuzaki K, Kubo H, Nishitani H. High-bvalue diffusion-weighted magnetic resonance imaging of pancreatic cancer and mass-forming chronic pancreatitis: preliminary results. Acta Radiol. 2008; 49:383-386.

10. Fattahi R, Balci NC, Perman WH, Hsueh EC, Alkaade S, Havlioglu N, Burton FR. Pancreatic diffusion-weighted imaging (DWI): comparison between mass-forming focal pancreatitis (FP), pancreatic cancer (PC), and normal pancreas. J Magn Reson Imaging. 2009; 29:350-356.

11. Wiggermann P, Grützmann R, Weissenböck A, Kamusella P, Dittert DD, Stroszczynski C. Apparent diffusion coefficient measurements of the pancreas, pancreas carcinoma, and massforming focal pancreatitis. Acta Radiol. 2012; 53:135-139.

12. Sandrasegaran K, Nutakki K, Tahir B, Dhanabal A, Tann M, Cote GA. Use of diffusion-weighted MRI to differentiate chronic pancreatitis from pancreatic cancer. Am J Roentgenol. 2013; 201:1002-1008.

13. Bilgili Y, Unal B. Effect of region of interest on interovserver variance in apparent diffusion coefficient measures. Am J Neuroradiol. 2004; 25:108-111.

14. Kim SH, Lee JY, Lee JM, Han JK, Choi BI. Apparent diffusion coefficient for evaluating tumour response to neoadjuvant chemoradiation therapy for locally advanced rectal cancer. Eur Radiol. 2011; 21:987-995.

15. Padhani AR, Liu G, Koh DM, Chenevert TL, Thoeny HC, Takahara T, Dzik-Jurasz A, Ross BD, Van Cauteren M, Collins D, Hammoud DA, Rustin GJ, Taouli B, et al. Diffusion-weighted magnetic resonance imaging as a cancer biomarker: consensus and recommendations. Neoplasia. 2009; 11:102-125.

16. Bammer R. Basic principles of diffusion-weighted imaging. Eur J Radiol. 2003; 45:169-184.

17. Kartalis N, Lindholm TL, Aspelin P, Permert J, Albiin N. Diffusion-weighted magnetic resonance imaging of pancreas tumours. Eur Radiol. 2009; 19:1981-1990.

18. Matsuki M, Inada Y, Nakai G, Tatsugami F, Tanikake M, Narabayashi I, Masuda D, Arisaka Y, Takaori K, Tanigawa N. Diffusion-weighed MR imaging of pancreatic carcinoma. Abdom Imaging. 2007; 32:481-483.

19. Ichikawa T, Erturk SM, Motosugi U, Sou H, Iino H, Araki T, Fujii H. High-b value diffusion weighted MRI for detecting pancreatic adenocarcinoma: preliminary results. Am J Roentgenol. 2007; 188:409-414. 
20. Muraoka N, Uematsu H, Kimura H, Imamura Y, Fujiwara Y, Murakami M, Yamaguchi A, Itoh H. Apparent diffusion coefficient in pancreatic cancer: characterization and histopathological correlations. J Magn Reson Imaging. 2008; 27:1302-1308.

21. Fattahi R, Balci NC, Perman WH, Hsueh EC, Alkaade S, Havlioglu N, Burton FR. Pancreatic diffusion-weighted imaging (DWI): comparison between mass-forming focal pancreatitis (FP), pancreatic cancer (PC), and normal pancreas. J Magn Reson Imaging. 2009; 29:350-356.

22. Lemke A, Laun FB, Klauss M, Re TJ, Simon D, Delorme S, Schad LR, Stieltjes B. Differentiation of pancreas carcinoma from healthy pancreatic tissue using multiple b-values: comparison of apparent diffusion coefficient and intravoxel incoherent motion derived parameters. Invest Radiol. 2009; 44:769-775.

23. Fukukura Y, Takumi K, Kamimura K, Shindo T, Kumagae Y, Tateyama A, Nakajo M. Pancreatic adenocarcinoma: variability of diffusion-weighted MR imaging findings. Radiology. 2012; 263:732-740.

24. Kamisawa T, Takuma K, Anjiki H, Egawa N, Hata T, Kurata M, Honda G, Tsuruta K, Suzuki M, Kamata N, Sasaki T. Differentiation of autoimmune pancreatitis from pancreatic cancer by diffusion-weighted MRI. Am J Gastroenterol. 2010; 105:1870-1875.

25. Wang Y, Miller FH, Chen ZE, Merrick L, Mortele KJ, Hoff FL, Hammond NA, Yaghmai V, Nikolaidis P. Diffusion-weighted MR imaging of solid and cystic lesions of the pancreas. Radio Graphics. 2011; 31:E47-64.

26. Rosenkrantz AB, Matza BW, Sabach A, Hajdu CH, Hindman N. Pancreatic cancer: Lack of association between apparent diffusion coefficient values and adverse pathological features. Clinical Radiology. 2012; 68:e191-197.
27. Park MJ, Kim YK, Choi SY, Rhim H, Lee WJ, Choi D. Preoperative detection of small pancreatic carcinoma: value of adding diffusion-weighted imaging to conventional MR imaging for improving confidence level. Radiology. 2014; 273:433-443.

28. Barral M, Sebbag-Sfez D, Hoeffel C, Chaput U, Dohan A, Eveno C, Boudiaf M, Soyer P. Characterization of focal pancreatic lesions using normalized apparent diffusion coefficient at 1.5 -Tesla: preliminary experience. Diagn Interv Imaging. 2013; 94:619-627.

29. Ma C, Liu L, Li J, Wang L, Chen LG, Zhang Y, Chen SY, Lu JP. Apparent diffusion coefficient (ADC) measurements in pancreatic adenocarcinoma: A preliminary study of the effect of ROI on ADC values and inter-observer variability. J Magn Reson Imaging. 2016; 43:407-413.

30. Legrand L, Duchatelle V, Molinié V, Boulay-Coletta I, Sibileau E, Zins M. Pancreatic adenocarcinoma: MRI conspicuity and pathologic correlations. Abdom Imaging. 2015; 40:85-94.

31. Klauss M, Lemke A, Grünberg K, Simon D, Re TJ, Wente MN, Laun FB, Kauczor HU, Delorme S, Grenacher L, Stieltjes B. Intravoxel incoherent motion MRI for the differentiation between mass forming chronic pancreatitis and pancreatic carcinoma. Invest Radio. 2011; 46:57-63.

32. Corona-Villalobos CP, Pan L, Halappa VG, Bonekamp S, Lorenz CH, Eng J, Kamel IR. Agreement and reproducibility of apparent diffusion coefficient measurements of dualb-value and multi-b-value diffusion-weighted magnetic resonance imaging at 1.5 Tesla in phantom and in soft tissues of the abdomen. J Comput Assist Tomogr. 2013; 37:46-51. 